\title{
A suspected case of Clostridium perfringens sepsis with intravascular hemolysis after transhepatic arterial chemoembolization: a case report
}

Haruki Uojima ${ }^{1,2^{*}}$, Mie Onoue ${ }^{2}$, Hisashi Hidaka², Naohisa Wada², Yoshiaki Tanaka², Tomoyoshi Inoue², Kousuke Kubota², Takahide Nakazawa ${ }^{2}$, Akitaka Shibuya ${ }^{2}$ and Wasaburo Koizumi ${ }^{2}$

\begin{abstract}
Introduction: Sepsis due to Clostridium perfringens, one of several clostridial species, is an important cause of massive intravascular hemolysis in patients with underlying malignancies. Chronic liver diseases,

immunosuppression, and presence of malignancies were risk factors for Clostridium perfringens sepsis. Therefore, Clostridium perfringens sepsis should always be considered in patients presenting with liver damage after chemoembolic therapy for hepatocellular carcinoma. This case report focuses on findings characteristic of an intravascular hemolysis due to Clostridium perfringens after transhepatic arterial chemoembolization.

Case presentation: An 83-year-old Japanese man presented to our hospital because of a third recurrence of hepatocellular carcinoma. He had nonalcoholic steatohepatitis-related cirrhosis, and underwent radiofrequency ablation and transhepatic arterial chemoembolization therapy for hepatocellular carcinoma of S4/S8 and S2. He had a medical history of pancreatic carcinoma and underwent pylorus-preserving pancreaticoduodenectomy approximately 5 years ago. Because follow-up computed tomography showed a recurrence of the hepatocellular carcinoma, he underwent transhepatic arterial chemoembolization with a hepatic arterial infusion of $20 \mathrm{mg}$ epirubicin, followed by $4 \mathrm{~mL}$ Lipiodol (ethiodized oil). On the sixth day after the procedure, he complained of fever and hematuria with jaundice. Laboratory findings indicated hemolysis and increased inflammatory response. Although we initiated antibiotic therapy combined with surgical debridement for infection after transhepatic arterial chemoembolization, he died within 6 hours. The autopsy showed a 4-cm local necrotic hepatic tumor. The cut surface revealed a tumor with an internal spongiform appearance, which was a pseudocystic and partially necrotic lesion. In addition, a diffuse spread of Gram-positive rods in multiple organs including the heart was histologically confirmed. The culture obtained by fluid aspiration from the hepatic abscess revealed Clostridium perfringens. Although the role of Clostridium perfringens was never established during the life of this patient, based on the clinical course and the culture from the hepatic abscess at postmortem, intravascular hemolysis secondary to Clostridium perfringens sepsis was suspected.
\end{abstract}

Conclusion: Intravascular hemolysis secondary to Clostridium perfringens should always be considered in patients presenting with liver damage after chemo-embolic therapy for hepatocellular carcinoma. Biliary reconstruction is an especially important risk factor for infection.

Keywords: Intravascular hemolysis, Clostridium perfringens, Transhepatic arterial chemoembolization

\footnotetext{
*Correspondence: kiruha@kitasato-u.ac.jp

'Department of Gastroenterology, Shonan Kamakura General Hospital,

1370-1 Okamoto, Kamakura, Kanagawa 247-8533, Japan

${ }^{2}$ Department of Gastroenterology, Internal Medicine, Kitasato University

School of Medicine, 1-15-1 Kitasato, Minami-ku, Sagamihara, Kanagawa

252-0375, Japan
}

(c) The Author(s). 2019 Open Access This article is distributed under the terms of the Creative Commons Attribution 4.0 International License (http://creativecommons.org/licenses/by/4.0/), which permits unrestricted use, distribution, and reproduction in any medium, provided you give appropriate credit to the original author(s) and the source, provide a link to the Creative Commons license, and indicate if changes were made. The Creative Commons Public Domain Dedication waiver (http://creativecommons.org/publicdomain/zero/1.0/) applies to the data made available in this article, unless otherwise stated. 


\section{Introduction}

Sepsis due to Clostridium perfringens, one of several clostridial species, is an important cause of massive intravascular hemolysis in patients with underlying malignancies [1, 2]. Although C. perfringens sepsis is rare, massive intravascular hemolysis due to $C$. perfringens sepsis can have a particularly rapid fatal clinical course [3]. A literature review showed that chronic liver diseases, immunosuppression, and presence of malignancies were risk factors for $C$. perfringens sepsis [4]. In particular, $C$. perfringens sepsis should always be considered in patients presenting with liver damage after chemo-embolic therapy for hepatocellular carcinoma ( $\mathrm{HCC}$ ). This case report focuses on findings characteristic of an intravascular hemolysis secondary to $C$. perfringens sepsis after transhepatic arterial chemoembolization (TACE).

\section{Case presentation}

An 83-year-old Japanese man presented to our hospital because of a third recurrence of HCC. He had nonalcoholic steatohepatitis-related cirrhosis, and underwent radiofrequency ablation for a partial HCC of S4/S8 in his liver 3 years ago. Because abdominal computed tomography $(\mathrm{CT})$ revealed multiple $\mathrm{HCC}$ of $\mathrm{S} 4 / \mathrm{S} 8$ and $\mathrm{S} 2$ in his liver 1 year ago, he underwent TACE therapy with an emulsified mixture of Lipiodol (ethiodized oil) and Farmorubicin (epirubicin) together with gelatin sponge particles for multiple tumors. After the second TACE, abdominal CT revealed sufficient Lipiodol (ethiodized oil) retention and the inefficacy of this treatment. However, follow-up CT showed a HCC recurrence in the left lobe 2 months ago. His medical history included reflux esophagitis, hypertension, and pancreatic carcinoma and he underwent pylorus-preserving pancreaticoduodenectomy approximately 5 years ago. His medications included amlodipine $5 \mathrm{mg}$, candesartan $4 \mathrm{mg}$, and esomeprazole $20 \mathrm{mg}$, all once daily. He was nondiabetic, did not smoke tobacco or drink alcohol, and had no history of any drug or food allergies. His family and social history were unremarkable. He appeared well on presentation. His body mass index was $26.2 \mathrm{~kg} / \mathrm{m}^{2}$, with no noticeable body weight changes. $\mathrm{He}$ had an axillary temperature of $36.0^{\circ} \mathrm{C}$, a heart rate of 70 beats/minute, and blood pressure of $118 / 52 \mathrm{mmHg}$, with an oxygen saturation of $98 \%$ on room air at admission. No conjunctival pallor, icterus, cyanosis, or spider nevi were detectable on physical examination. Cardiovascular and respiratory examinations indicated normal jugular venous pressure and heart sounds, with no detectable murmurs, and normal breath sounds, with no crackle or wheeze. There were no particular abnormal physical findings. Laboratory studies indicated elevated creatinine and $\alpha$-fetoprotein levels (Table 1 ). Abdominal ultrasonography showed several hypoechoic masses in his liver; an abdominal plane CT showed multiple lesions with the greatest extent more than $40 \mathrm{~mm}$ in the left lobe of his liver (Fig. 1).

Owing to our patient's high risk of liver abscess after TACE because of his medical history of pancreaticoduodenectomy, the treatment course was carefully decided after consultation with our patient and his family. He underwent TACE with a hepatic arterial infusion of 20 mg epirubicin, followed by $4 \mathrm{~mL}$ Lipiodol (ethiodized oil) (Fig. 2). A few days after undergoing the procedure, he was generally well except for mild symptoms attributed to postembolization syndrome. Despite antibiotic therapy (cefmetazole 3 grams daily) to prevent infection, he complained of fever, nausea, and hematuria on the sixth day after the procedure. He appeared unwell, severely jaundiced, and extremely restless. When his condition deteriorated, he had an axillary temperature of $39.0^{\circ} \mathrm{C}$, a heart rate of 110 beats/minute, and blood pressure of $90 / 40 \mathrm{mmHg}$. He presented with deterioration in hemoglobin levels and renal function, anemia, and a coagulation dysfunction. Furthermore, total bilirubin and direct bilirubin levels increased. Because elevated bilirubin and lactate dehydrogenase due to destruction of red blood cells showed hemolytic anemia, we performed a Coombs test for autoimmune hemolytic anemia to detect the presence of antibodies against red blood cells. However, the results for both the direct and indirect Coombs tests were negative. Based on our patient's severe clinical course and laboratory data suggestive of hemolysis, intravascular hemolysis secondary to $C$. perfringens sepsis was suspected.

Because the embolic and necrotic lesion after TACE was suspected to be the focus of infection, we initiated antibiotic therapy (piperacillin/tazobactam 4.5 grams and clindamycin $600 \mathrm{mg}$ ) combined with surgical debridement. However, he died within 6 hours following unsuccessful cardiopulmonary resuscitation. An autopsy showed a 4-cm local, necrotic, hepatic tumor. The cut surface revealed a tumor with an internal spongiform appearance, which was a pseudocystic and partially necrotic lesion (Fig. 3). In addition, a diffuse spread of Gram-positive rods in multiple organs including the heart was histologically confirmed (Fig. 4). The culture obtained by fluid aspiration from the hepatic abscess revealed $C$. perfringens.

\section{Discussion}

We reported a suspected case of massive intravascular hemolysis due to $C$. perfringens after TACE. In the present case, the role of $C$. perfringens was never established during the life of the patient. However, based on the severe clinical course and the culture obtained by fluid aspiration from the hepatic abscess at postmortem, intravascular hemolysis secondary to C. perfringens sepsis was suspected. 
Table 1 Summary of the laboratory data

\begin{tabular}{|c|c|c|c|c|}
\hline & & Normal range & Before procedure & The sixth day after the procedure \\
\hline \multicolumn{5}{|l|}{ Complete blood count } \\
\hline White blood cells & $\times 10^{2 /} \mu \mathrm{L}$ & $30-97$ & 40 & 291 \\
\hline Neutrophils & $\%$ & $36.6-79.9$ & 70.1 & 92 \\
\hline Hemoglobin & $\mathrm{g} / \mathrm{dL}$ & $13.1-17.6$ & 9.3 & 5.1 \\
\hline Platelet counts & $\times 10^{4 /} \mu \mathrm{L}$ & $12.4-30.5$ & 11.6 & 11.4 \\
\hline \multicolumn{5}{|l|}{ Biochemistry } \\
\hline Total bilirubin & $\mathrm{mg} / \mathrm{dL}$ & $0.1-1.2$ & 0.7 & 14 \\
\hline Aspartate aminotransferase & $\mathrm{IU} / \mathrm{L}$ & $12-35$ & 33 & 1300 \\
\hline Alanine aminotransferase & $\mathrm{IU} / \mathrm{L}$ & $6-40$ & 76 & 362 \\
\hline Lactate dehydrogenase & IU/L & $119-229$ & 235 & 4523 \\
\hline$\gamma$-glutamyl transpeptidase & $\mathrm{IU} / \mathrm{L}$ & $0-48$ & 82 & 108 \\
\hline Alkaline phosphatase & IU/L & $115-359$ & 427 & 751 \\
\hline Blood-urea-nitrogen & $\mathrm{mg} / \mathrm{dL}$ & $7.4-19.5$ & 32.8 & 45.9 \\
\hline Creatinine & $\mathrm{mg} / \mathrm{dL}$ & $0.5-1.2$ & 1.35 & 1.50 \\
\hline Total protein & $\mathrm{g} / \mathrm{dL}$ & $6.4-8.3$ & 6.7 & 6.0 \\
\hline Albumin & $\mathrm{g} / \mathrm{dL}$ & $3.8-5.2$ & 3.2 & 2.4 \\
\hline Sodium & $\mathrm{mEq} / \mathrm{L}$ & $135-147$ & 140 & 132 \\
\hline Potassium & $\mathrm{mEq} / \mathrm{L}$ & $3.4-4.8$ & 4.1 & 4.7 \\
\hline Ammonia & $\mu \mathrm{g} / \mathrm{dL}$ & $12-66$ & 102 & 145 \\
\hline $\mathrm{HbA1c}$ & $\%$ & $4.6-6.2$ & 5.5 & \\
\hline \multicolumn{5}{|l|}{ Coagulation } \\
\hline PT-INR & & $0.89-1.12$ & 1.04 & 1.58 \\
\hline APTT & seconds & $23.6-31.3$ & 22.9 & 44.1 \\
\hline \multicolumn{5}{|l|}{ Tumor marker } \\
\hline Alpha-fetoprotein & $\mathrm{ng} / \mathrm{mL}$ & $0-10$ & 36,690 & \\
\hline PIVKA-II & $\mathrm{mAU} / \mathrm{mL}$ & $0-39$ & 3743 & \\
\hline \multicolumn{5}{|l|}{ Serology } \\
\hline Hepatitis B surface antigen & & & negative & \\
\hline Hepatitis C virus antibody & & & negative & \\
\hline
\end{tabular}

APTT activated partial thromboplastin time, HbA1c glycated hemoglobin, PIVKA-II protein induced by vitamin $\mathrm{K}$ absence-II, PT-INR prothrombin time-international normalized ratio

C. perfringens is an anaerobic Gram-positive rod that is naturally found in the intestines of humans and wild animals [4]. Although C. perfringens sepsis is rare, its association with massive hemolysis is well known, with death occurring within hours of presentation in patients similar to the present case [5-7]. The alpha toxin produced by $C$. perfringens is primarily responsible for the disease pathogenesis. This toxin, which possesses phospholipase $\mathrm{C}$ and sphingomyelinase activities, can damage the structural integrity of the red blood cell membrane, leading to spherocytosis and subsequent hemolysis $[8,9]$.

A review of studies on hemolysis associated with $C$. perfringens in the literature showed that infection was attributed to immunosuppression related to ageing, chronic disease, and presence of malignancies [10]. As the infected focus was commonly the liver and gastrointestinal tract, suspecting $C$. perfringens sepsis after TACE for HCC in liver cirrhosis was reasonable. Therefore, $C$. perfringens sepsis should always be considered in the differential diagnosis of $\mathrm{HCC}$ in patients presenting with fever and hemolysis after the procedure.

According to a search of reports in PubMed using the medical subject terms "TACE/transarterial embolization (TAE)," "clostridial sepsis," and/or "hemolysis," there were five cases of intravascular hemolysis secondary to C. perfringens sepsis after TACE/TAE [11-13] (Table 2). The median age of patients at presentation was 74 years (range, 70-83 years), with all five patients being male. Some patients had important risk factors for infection in 


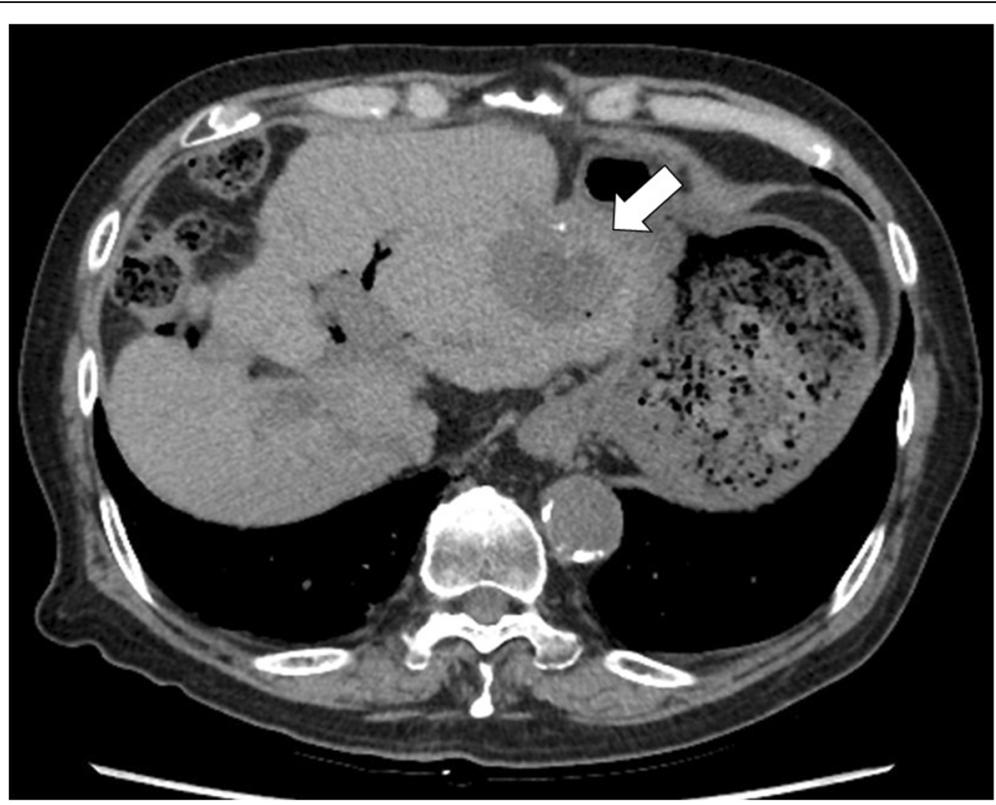

Fig. 1 Computed tomography images in the axial plane. A low-density nodule (white arrow) in the left lobe is shown. Dynamic computed tomography was difficult to perform in this patient because of decreased renal function

the gastrointestinal tract, such as gastrectomy, or invasive endoscopic procedures, resulting in tissue damage. In particular, TACE for HCC after biliary reconstruction including pancreaticoduodenectomy should be avoided as much as possible because severe liver abscess could frequently occur. The median tumor diameter was $99 \mathrm{~mm}$ (range, $40-179 \mathrm{~mm}$ ). In all cases of infection after TACE, epirubicin, doxorubicin, and oxaliplatin were administered, with epirubicin being the most frequently used.

The common symptoms of sepsis associated with hemolysis were hematuria, fever, and hypotension, which began within 1 week (range, 1-6 days) after the procedure. Although some reports did not mention laboratory

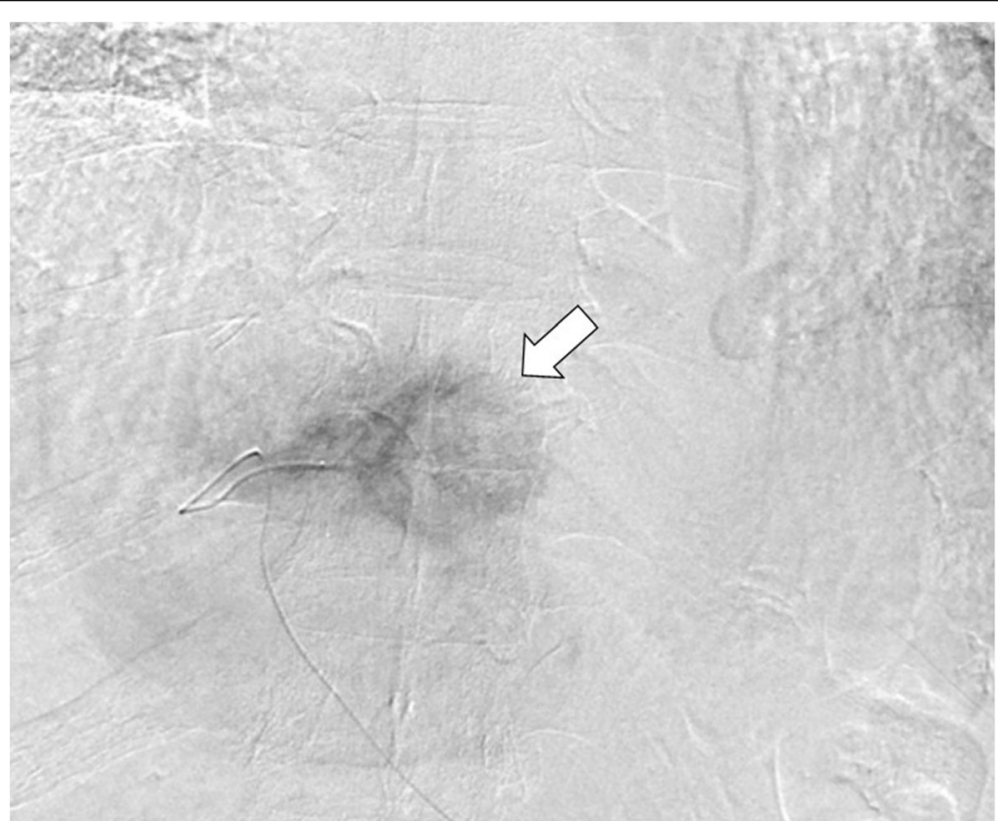

Fig. 2 Hepatic angiogram showing a large 40-mm hepatic tumor corresponding to the lesion on plane computed tomography. The hypervascular tumor in the left lobe is depicted as a round mass of contrast opacification (straight white arrow) and as being supplied by the left hepatic artery 


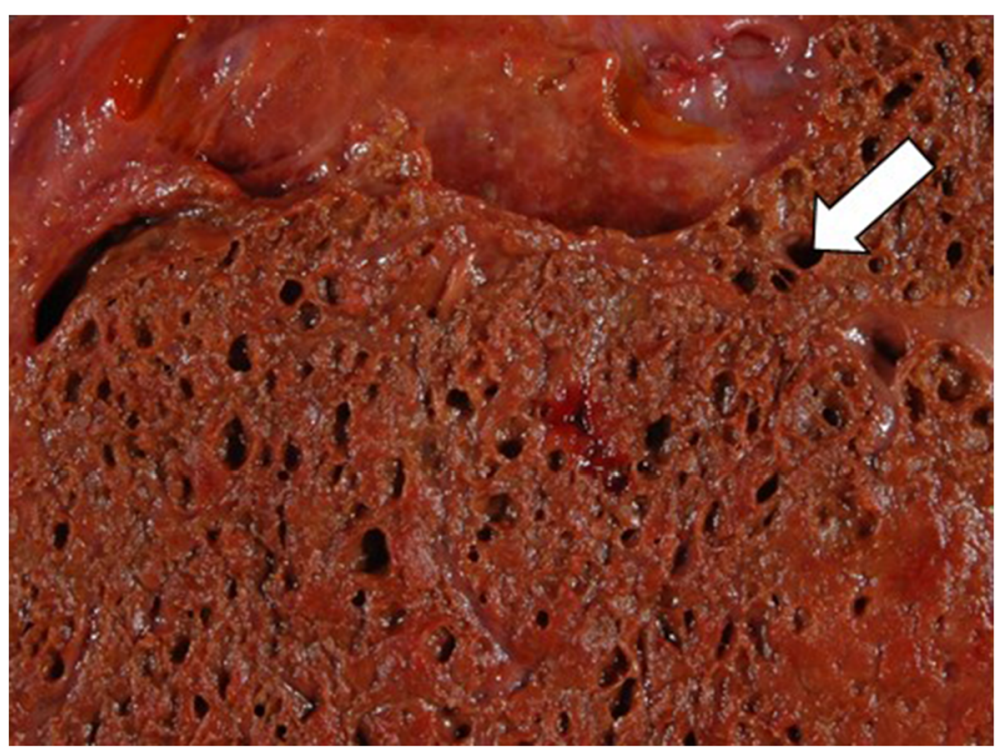

Fig. 3 Gross appearance of the liver at autopsy. The cut surface revealed a tumor with an internal spongiform appearance, that of a pseudocystic and partially necrotic lesion measuring $50 \mathrm{~mm}$ in the maximum dimension (white arrowhead)

data, the review showed a decrease in the median hemoglobin level from pre-procedure $(11.6 \mathrm{mg} / \mathrm{dL})$ to the occurrence of hemolysis $(6.6 \mathrm{mg} / \mathrm{dL})$. An increase in the median total bilirubin level from $1.15 \mathrm{mg} / \mathrm{dL}$ to $11.9 \mathrm{mg} / \mathrm{dL}$, an increase in the median aspartate aminotransferase (AST) level from 73 to $1626 \mathrm{IU} / \mathrm{L}$, and an increase in the alanine aminotransferase (ALT) level from 110.5 to $1337 \mathrm{IU} / \mathrm{L}$ was observed at hemolysis associated with $C$. perfringens. Of note, a few cases showed that liver function enzyme levels at post-procedure were elevated compared with those at pre-procedure. Liver damage after chemo-embolic therapy for HCC may be a high risk factor for $C$. perfringens infection.

Imaging studies, especially ultrasonography and CT, showed multiple hypovascular lesions, but it was difficult to distinguish hepatic abscesses from tumors because there were no diagnostic features of hepatic abscesses after TACE/TAE for HCC. Therefore, diagnosis was bacteriologically confirmed through identification of the presence of $C$. perfringens in the blood culture or the abscess.

With respect to treatment, all the patients received antibiotic therapy, and two patients underwent surgery. The mortality rate was $60.0 \%$, with a median time to death of 9.7 hours (range, 0-96 hours). In all fatal cases, patients already went into shock or died before a diagnosis and decision to operate could be made. In one patient who survived, surgical drainage in combination with appropriate antibiotic therapy may have improved survival. If there was a perceived infected focus such as a hepatic abscess, the recommended treatment included aggressive surgical drainage together with high-dose antibiotic therapy.
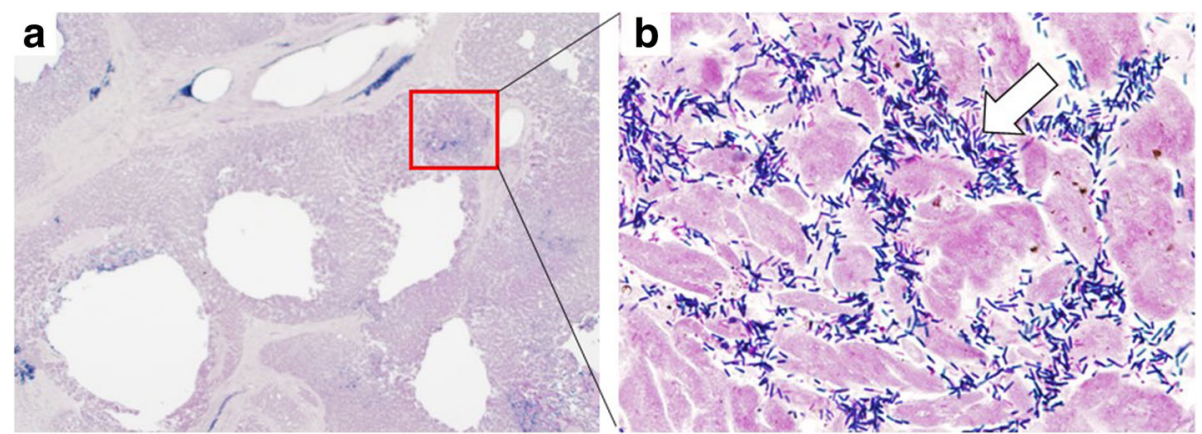

Fig. 4 a Pathogenesis of multiple small abscesses. These abscesses contained a thin rim of epithelioid histiocytes and other inflammatory cells (Gram stain $\times 10)$. b Colonies of Gram-positive rods observed on Gram staining (arrows) in the heart (Gram stain $\times 550$ ) 


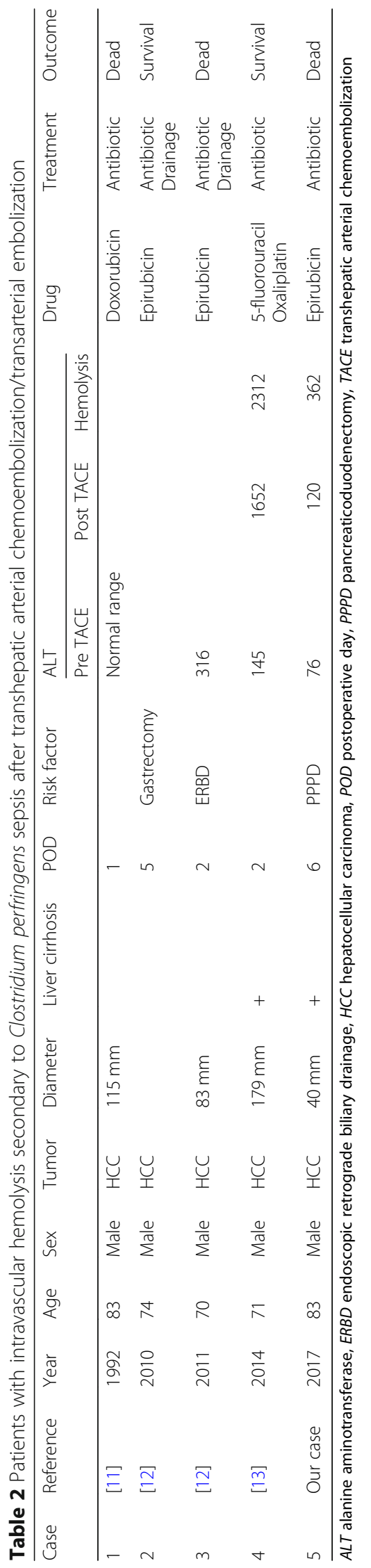




\section{Conclusion}

Intravascular hemolysis secondary to $C$. perfringens should always be considered in patients who present with liver damage after chemo-embolic therapy for HCC. Biliary reconstruction is an especially important risk factor for infection.

\section{Abbreviations}

CT: Computed tomography; HCC: Hepatocellular carcinoma; TACE: Transhepatic arterial chemoembolization; TAE: Transarterial embolization

\section{Acknowledgements}

We thank Robert E. Brandt, founder, CEO, and CME of MedEd Japan, for editing the manuscript.

\section{Funding}

No funding was received.

\section{Availability of data and materials}

Not applicable.

\section{Authors' contributions}

$\mathrm{MO}, \mathrm{HU}, \mathrm{HH}, \mathrm{NW}, \mathrm{YT}, \mathrm{TI}, \mathrm{KK}, \mathrm{TN}, \mathrm{AS}$, and WK contributed equally to this work. $\mathrm{HU}$ and $\mathrm{MO}$ collected and analyzed the data; $\mathrm{MO}$ drafted the manuscript; $\mathrm{HH}$, NW, YT, TI, KK, TN, AS, and WK offered technical or material support. All authors have read and approved the final version of the manuscript to be published.

\section{Ethics approval and consent to participate}

Not applicable.

\section{Consent for publication}

Written informed consent was obtained from the patient's next of kin for publication of this case report and any accompanying images. A copy of the written consent is available for review from this journal.

\section{Competing interests}

The authors declare that they have no competing interests.

\section{Publisher's Note}

Springer Nature remains neutral with regard to jurisdictional claims in published maps and institutional affiliations.

Received: 3 July 2018 Accepted: 20 February 2019

Published online: 27 April 2019

\section{References}

1. Martí Gelonch L, Jiménez Agüero R, Rodríguez Canas N, Enríquez Navascués JM. Massive haemolysis due to sepsis caused by Clostridium perfringens secondary to liver abscess. Presentation of two cases with a similar history. Gastroenterol Hepatol. 2018;41(9):562-3. https://doi.org/10.1016/j.gastrohep. 2017.11.012

2. García Carretero R, Romero Brugera M, Vazquez-Gomez O, Rebollo-Aparicio N. Massive haemolysis, gas-forming liver abscess and sepsis due to Clostridium perfringens bacteraemia. BMJ Case Rep. 2016; https://doi.org/10. 1136/bcr-2016-218014

3. Lim AG, Rudd KE, Halliday M, Hess JR. Hepatic abscess-associated Clostridial bacteraemia presenting with intravascular haemolysis and severe hypertension. BMJ Case Rep. 2016; https://doi.org/10.1136/bcr-2015-213253.

4. Shindo Y, Dobashi Y, Sakai T, Monma C, Miyatani H, Yoshida Y. Epidemiological and pathobiological profiles of Clostridium perfringens infections: review of consecutive series of 33 cases over a 13-year period. Int J Clin Exp Pathol. 2015;8:569-77.

5. Dutton D, Gavrilova N. Massive intravascular hemolysis with organ failure due to Clostridium perfringens: evidence of intracytoplasmic C. perfringens. Blood. 2013;122:310.

6. Ingimarsdottir IJ, Asmundsdottir LR, Gottfredsson M. Case of the month: patient with septic shock and massive intravascular haemolysis. Laeknabladid. 2012;98:289-90.
7. $\mathrm{Ng} \mathrm{H}$, Lam SM, Shum HP, Yan WW. Clostridium perfringens liver abscess with massive haemolysis. Hong Kong Med J. 2010;16:310-2.

8. Ochi S, Oda M, Nagahama M, Sakurai J. Clostridium perfringens alpha-toxininduced hemolysis of horse erythrocytes is dependent on Ca2+ uptake. Biochim Biophys Acta. 2003;1613:79-86.

9. Sakurai J, Nagahama M, Oda M. Clostridium perfringens alpha-toxin: characterization and mode of action. J Biochem. 2004;136:569-74.

10. van Bunderen CC, Bomers MK, Wesdorp E, Peerbooms P, Veenstra J. Clostridium perfringens septicaemia with massive intravascular haemolysis: a case report and review of the literature. Neth J Med. 2010;68:343-6.

11. Gerson LB, Pont A, Cummins RT. Clostridial bacteremia and death following chemoembolization for hepatocellular carcinoma. J Vasc Interv Radiol. 1994; 5:167-70.

12. Oshima S, Takaishi K, Tani N, Hirano M, Ikeda K, Makari Y, et al. Two cases of liver abscess caused by Clostridium perfringens after transcatheter arterial chemoembolization. Gan To Kagaku Ryoho. 2013;40:1795-7.

13. Li JH, Yao RR, Shen HJ, Zhang L, Xie XY, Chen RX, et al. Clostridium perfringens infection after transarterial chemoembolization for large hepatocellular carcinoma. World J Gastroenterol. 2015;21:4397-401.

\section{Ready to submit your research? Choose BMC and benefit from:}

- fast, convenient online submission

- thorough peer review by experienced researchers in your field

- rapid publication on acceptance

- support for research data, including large and complex data types

- gold Open Access which fosters wider collaboration and increased citations

- maximum visibility for your research: over $100 \mathrm{M}$ website views per year

At BMC, research is always in progress.

Learn more biomedcentral.com/submissions 